\title{
Clément Rosset, El objeto singular, trad. Santiago E. Espi- nosa, México: Sexto Piso 2007, 132 pp.
}

\section{La desolación de la filosofía y el saber enamorado}

La raíz del pensamiento metafísico no es la postulación de otra realidad, o de una verdad absoluta sino que, en cualquier caso, es consecuencia de la incapacidad para aceptar, para amar en definitiva, la realidad y el saber de la misma. Es decir, la desolación por lo real, que conduce a la búsqueda de un otro, de un doble tranquilizador. Es justamente la excepción a esto, es decir, un saber alegre, afirmador, lo que rescata Rosset de Nietzsche. En este libro es posible encontrar justamente la exposición de aquella raíz.

Será en la afirmación según la cual «el enigma de la música es el enigma mismo de lo real» (p. 103), que puede encontrarse el eje en torno al cual giran las reflexiones de Rosset en este libro. Será especialmente la música lo que le brinde al autor la oportunidad de vislumbrar una filosofía, una forma de saber, que prescinda de consideraciones metafísicas. Y es que la filosofía ha corrido casi siempre, en efecto, por los cauces de la metafísica, es decir, no ha sido capaz de considerar la realidad sino por contraste, por el rodeo a través de un otro contrapuesto. Si lo propio de la filosofía es la interpretación de lo real, «¿cómo proceder a tal interpretación sin el auxilio de una instancia exterior? El mundo y su interpretación, programa de la filosofía, suponen a la vez la existencia del mundo y la de lo otro del mundo, o sea, una duplicación de lo real a la cual invita toda metafísica» (p. 115). Tal es al menos la vía metafísica a la que Rosset parece haber encontrado una alternativa.

¿Qué es en suma lo real para Rosset? Precisamente lo que carece de doble, lo que es sólo sí mismo, lo que no es ninguna otra cosa, es decir, el objeto singular. Esto lo hace a la vez lo más escurridizo, pues identificar algo desconocido es, justamente compararlo con algo conocido: «Lo real existe - dice Rosset-, pero es imposible precisar cuál; igual que aquí existe, pero es imposible precisar dón- 
de» (p. 29). El mundo mismo termina en efecto plagado de «imágenes, de remisiones, de referencias y de reflejos» cuya proliferación diluye su propia realidad «sin cesar en el juego de la réplica y en el espacio del punto de vista» (p. 77). Unas cosas remiten a otras como el nudo en el pañuelo al recuerdo, como algo extraño, ajeno. La misma función del pañuelo requiere de un recordatorio análogo, de modo que el pensamiento al cabo tiene que elegir entre la tautología de lo real y el extravío del doble, con cuya palidez contrasta la vivacidad de lo real. Rosset nos muestra a este respecto dos paradojas: por un lado, lo real singular, idéntico únicamente a sí mismo, permanece en esa misma medida «refractario a toda empresa de identificación» (p. 27); y por otro lado, el doble de lo real, que pretende suplirlo, lo evoca. De lo anterior Rosset extrae dos principios que rigen el desarrollo de su texto. Primer principio: «cuanto más un objeto es real, tanto más es inidentificable». Segundo principio: «cuanto más intenso es el sentimiento de lo real [i.e., el sentimiento de que cierta cosa es real], tanto más es indescriptible y oscuro» ( $\mathrm{p}$. 43). Esto no significa, sin embargo, que lo real en cuanto tal, en su singularidad e inidentificabilidad, nos sea inaccesible. De hecho lo experimentamos así, sólo que no somos capaces de describir adecuadamente lo real experimentado. Aquí es donde la música viene al caso, junto a otras experiencias a través de las cuales es posible percibir lo real en tanto que inidentificable y singular, a saber: la de la risa, lo terrorífico, del deseo, la cinematográfica y, por encima de todas, la musical.

De acuerdo a Rosset, la risa es una manifestación de la súbita aparición de lo real frente a nosotros: el efecto cómico no responde sólo, y no principalmente, a la forma en que lo real desmiente a su representación (teoría clásica de lo cómico), sino que lo real mismo puede ser absurdo (i.e., carecer de razón, de fundamento, de sentido). Sin embargo, la naturaleza del efecto cómico no deja de ser oscura, sólo que tal oscuridad «es aquí el índice de una profundidad, en este caso de la más grande profundidad de lo cómico, que es la de aproximar la singularidad a lo real - a su propio misterio-» (46-47 pp). Ahora bien, puesto que la realidad misma carece de todo fundamento exterior a ella, entonces todo lo real es cómico, por el sólo hecho de existir. Así, mientras que la risa se manifiesta 
«como un regocijo incomprensible con respecto a lo real, el miedo, así, también se presenta como una inquietud igual de incomprensible con respecto a lo irreal» (48-49 pp). Por lo general el efecto de lo terrorífico se explica (caso de Freud por ejemplo) como la incertidumbre acerca de si algo es o no real, si ese algo sigue siendo ese mismo algo, o sólo lo parece. Pero en tal caso, señala Rosset, cualquier cosa habría de resultarnos terrorífica, en la medida en que no hay identidad que no se preste a semejante duda. Ante ello se nos propone otra hipótesis: «lo otro que da miedo no es lo desconocido, sino lo conocido en tanto que otro. El objeto terrorífico es entonces lo real en persona, percibido como insólito y bizarro. El objeto terrorífico se confunde así con el objeto cómico; uno y otro son atribuibles a un mismo efecto de lo real» (50-51 pp). ¿Por qué en un momento lo real tiene un efecto de regocijo en la risa y al momento siguiente uno terrorífico? No por otra cosa sino por lo que se espera de él, a saber, en el caso de lo terrorífico o de las catástrofes, que en definitiva no se presenten.

Por lo que se refiere al deseo, Rosset también responde a la teoría más extendida, que «explica el mecanismo del deseo no por la presencia de un objeto deseable o deseado, sino más bien por su ausencia, o incluso por su presencia "imaginaria" o "simbólica" » (p. 54). De esa forma se afirma que lo real por sí sólo no es objeto de deseo, sino que sólo puede serlo en tanto que ausencia, lo que lo hace a la vez inalcanzable. Según esto, cualquier objeto del deseo sólo puede ser tal en tanto no sea lo real mismo, sino algo que lo suple, o simplemente su eterna lejanía (el mundo acaba por ser algo en absoluto deseable). En resumen, el «objeto del deseo está para siempre ausente, y la experiencia del deseo es la experiencia de esta misma ausencia» (p. 58). Pues bien, para Rosset ocurre justamente lo opuesto: el deseo no desprecia lo real (confinándolo a una eterna lejanía), sino que lo aprecia tanto que «retarda el instante de consumirlo hasta el momento ilusorio en que estaría en estado de gozar de él enteramente, no acepta un placer a menos que se acompañe de un vistazo al conjunto de los demás placeres posibles» (p. 61). Así, el deseo es índice de la riqueza inagotable de lo real, que lo presenta como infinitamente deseable.

Rosset encuentra en dos formas del arte cinematográfico la 
ocasión de que lo real se presente ante nosotros, a saber, el cine fantástico y lo que él llama «la opción "realista"» (Jean-Luc Godard). El cine fantástico, que evoca lo otro (el monstruo, el muerto viviente...), evoca así mismo, repentinamente, lo mismo: «señala la singularidad de lo real en la exacta medida en que sobresale para sugerir sus eventuales duplicaciones, sus monstruosas alteraciones» (p. 68). Mientras que en el género fantástico lo otro pretende ser lo mismo (el doble pretende ser el original), en el cine realista, a la inversa, es lo real mismo lo que aparece como algo fantástico «y lo mismo toma un instante el rostro de lo otro [...] simplemente porque no había sido nunca antes percibido como tal» (p. 69).

Pero es en la experiencia musical donde más palmariamente lo real se muestra justamente como tal. Esto tiene relación con el hecho de que la música, a diferencia de todas las otras artes, no es representativa, no es un arte imitativo, no intenta hablar de algo más. En virtud de ello mismo se puede atribuir a la música el grado máximo de expresividad. La música se presenta así como algo desligado de cualquier otra realidad, independiente, «extranjero, indiferente, casi diríase irreal a juzgar por la soltura [...] con la que se desolidariza de toda realidad distinta de ella misma» (74-75 pp). La presentación del objeto musical ejerce en nosotros una fascinación inversa a la que pretende ocasionar el prestidigitador. Mientras que éste atrae las miradas hacia donde nada ocurre, fingiendo lo opuesto y ocultando el lugar en el que sí ocurre el asunto, la música en cambio hace visible lo que realmente ocurre, burlándose «aún de lo más visible y reconocido como tal» (p. 75). Más aún, el efecto musical propiamente dicho consiste en la aniquilación de todo pensamiento, sentimiento y cualquier reacción afectiva distinta de él mismo. En todo caso, el objeto musical no remite más que a sí mismo, a su sola singularidad. Esto le permite a Rosset decir que en la música se da una irrupción «de lo real en estado bruto, sin posibilidad de acercamiento por medio de la representación» (p. 76). La fuerza que la música tiene sobre nosotros (la referencia a Orfeo es ineludible) es en última instancia la fuerza de lo real mismo, puesto que es justamente lo real lo que siempre nos sorprende del mundo, aquello a lo que no acabamos de habituarnos nunca, y la pieza musical se presenta como algo que no podemos referir 
a ninguna otra cosa, esto es, singularísimo, si se me permite la expresión, y en esa misma medida también como un ens realissimum. Es por eso que la música, señala Rosset, siempre nos toma por sorpresa. El único sentido en que para este autor se puede decir que la música imita a lo real, es aquél por el que se dice que la música imita el acto de devenir real, y no a algo real una vez advenido. La música presenta lo real presentándose a sí misma en toda su singularidad, y contrastando así con lo otro real que forma parte del ambiente. Esta peculiaridad de la música, considerada como lenguaje, de no remitir a nada más que a ella misma - «significante sin significado, o con una especie de significación "en blanco"» (p. 90) - hace de ella justamente la lengua universal: "porque es intraducible, no hay allí nada que traducir» (p. 98). Pero no sólo eso, acaso en el elemento rítmico de la música se encuentre la semilla de toda significación, de todo sentido. En el ejemplo del niño que no conoce del lenguaje más que su aspecto musical, y prescinde de las palabras para expresarse, puede verse que en el fondo uno sabe que no es necesario mucho más para lograr comprensión: «El que sabe canturrear ya sabe, en suma, todo lo que tendrá que decir del mundo: al escucharlo balbucear se siente que [...] sabe en general de qué se trata - en una palabra, para retomar una expresión que designa precisamente al hombre avisado del sentido de las cosas y de lo que quiere decir hablar, que "conoce la música" —» (p. 101).

Vista la música de esta manera, el goce que produce, su carácter jubilatorio, se vuelve especialmente enigmático. En efecto, no es posible explicarlo por la referencia de la música a algo más, puesto que tal referencia no se da, de modo que sólo queda pensar que la música produce ese goce únicamente por el hecho de estar ahí, de ser, de ser real. Lo prodigioso de la música, y de la realidad en general, es simplemente que existe. Así, lo que se señalaba al inicio, «como el enigma de la música es el enigma mismo de lo real, el enigma del placer que ella suscita es el enigma de la dicha suscitada con motivo del sentimiento de la existencia en general» (p. 103). Ahora bien, este júbilo musical contrasta con lo que resulta común en la filosofía, a saber, la consideración de que «lo real sólo es admisible bajo la reserva de enmiendas» (p. 112), de que por sí sola - por su mera existencia-, la realidad no sólo no es deseable, 
sino que es incluso lo contrario. En esta desolación filosófica - que puede sintetizarse como «la incapacidad afectiva de admitir que el ser humano habita un mundo en el que no hay historia - en donde no pasa nada-» (p. 113), es decir, la realidad tal cual, sin doble alguno-, encuentra Rosset el trasfondo de toda postura metafísica. A la pregunta de si es posible la percepción de lo real en cuanto tal, es decir, sin pasar por lo otro, sin el recurso del doble, la metafísica siempre responde que «la interpretación de lo existente tiene por condición el recurso a lo otro» (p. 116). Es precisamente la experiencia musical la que desmiente a la eterna respuesta de la metafísica, ya que en ella se vislumbra «una experiencia que testimonia un pensamiento sin segunda intención, una percepción de lo real que omite cualquier referencia a lo otro» (p. 117), a saber, la alegría. En resumen, se trata de «una aprobación de la existencia que consiste en estimar [...] que lo real es "suficiente" - es decir, que se basta a sí mismo, y basta además para colmar cualquier espera concebible de dicha-» (p. 117). De esta forma la alegría se muestra incluso como la disposición de ánimo más adecuada al saber, en la medida en que en ella lo real se muestra como algo interesante por sí mismo. Ahora bien, la alegría no se reduce a un sentimiento, sino que implica el saber de lo real y su aceptación a través de ese saber. Se trata de un saber que ama, de un saber enamorado, indica Rosset, justamente porque acepta incondicionalmente lo real tal y como se presenta, sin máscaras. La alegría es pues, en síntesis, «un saber aprobador de lo real» (p. 132), que constituye la base de toda alternativa al pensamiento filosófico. Ahí donde todavía esté presente la desolación filosófica, incluida la amargura moderna, se sigue pensando metafísicamente.

Jorge Alfonso Chávez Gallo Departamento de Filosofía Universidad Autónoma de Aguascalientes 